\title{
ALGORITMIZAÇÃO DO PROJETO ARQUITETÔNICO EM BIM: UMA APLICAÇÃO NA INDÚSTRIA DE BANHEIROS PRÉ-FABRICADOS
}

\section{ARCHITECTURAL DESIGN ALGORITHMIZATION IN BIM: AN APPLICATION IN THE PREFABRICATED BATHROOM INDUSTRY}

Verley Henry Côco Júnior ${ }^{1}$, Gabriela Celani ${ }^{2}$

\section{RESUMO:}

Os benefícios da Modelagem da Informação da Construção e dos algoritmos no projeto de arquitetura já são conhecidos e amplamente divulgados na literatura. Entretanto, a consolidação de um fluxo de trabalho no dia a dia dos escritórios integrando esses dois campos do conhecimento ainda não está plenamente estabelecido, mesmo em países com maior grau de industrialização. Este artigo tem como objetivo descrever um procedimento que integra essas duas tecnologias no projeto arquitetônico, em uma aplicação voltada para a pré-fabricação de banheiros. Para tanto, adotou-se uma metodologia exploratória e incremental de desenvolvimento de software em uma abordagem baseada em regras para a geração automatizada de layouts de banheiros. Os resultados demonstram que a definição de regras por meio de algoritmos elimina trabalhos repetitivos e desnecessários, assim como erros de montagem. Deste modo, novos horizontes se abrem para a atuação dos arquitetos mais próxima da industrialização da construção, da otimização de processos e da redução de custos desde as etapas iniciais de projeto.

PALAVRAS-CHAVE: Automatização de layout; Sistema generativo; Projeto paramétrico; Grasshopper.
Fonte de Financiamento: Fundação de Amparo à Pesquisa do Estado de São Paulo. Processos 17/221050 e $17 / 09702-9$

Submetido em: 17/01/2021 Aceito em: 19/02/2021

How to cite this article:

CÔCO Jr, V. H. CELANI, G. Algoritmização do projeto arquitetônico em BIM: uma aplicação na indústria de banheiros pré-fabricados. Gestão \& Tecnologia de Projetos. São Carlos, v16, n2, 2021. https://doi.org/10.11606/gtp.v16i2.181038 


\section{INTRODUÇÃO}

Nossa sociedade encontra-se em uma rápida transformação tecnológica, que se deve, em grande parte, aos avanços da Inteligência Artificial (IA) e do poder computacional associado à produção e análise de informações (ALPAYDIN, 2016). Na construção civil não é diferente. Isso se evidencia pelo crescente número de artigos publicados que discutem a aplicação das tecnologias de informação no ambiente construído. Os trabalhos dessa temática começaram a aparecer por volta da década de 1970, porém é a partir da virada do milênio quando ocorre um crescimento exponencial dessas publicações, o que demonstra a relevância crescente da área (DARKO, 2020).

Dentro deste contexto, um dos temas que se destaca é a Modelagem da Informação da Construção (BIM) (DARKO, 2020). Esse paradigma é considerado estratégico, pois habilita a construção civil para a Era da Informação, permitindo o engate de diversas tecnologias e modelos de negócio associadas à indústria 4.0 (OESTERREICH; TEUTEBERG, 2016). Internet das coisas (IoT), blockchain, digital twins, realidade virtual e aumentada são exemplos de tecnologias que podem ser associadas ao BIM. Apesar da Arquitetura, Engenharia e Construção (AEC) serem comumente identificados como lentos em aplicarem essas mudanças, a crescente difusão do BIM, inclusive com incentivos governamentais, pode acelerar estes processos (ABANDA; TAH; CHEUNG, 2017; ESTRATÉGIA BIM BR, 2009).

Especificamente no campo da arquitetura, as demandas e possibilidades provenientes das recentes discussões sobre tecnologia permeiam todo ciclo do edifício, isto é, desde a sua concepção, detalhamento, construção e manutenção até a sua demolição, o que tem fomentado discussões sobre quais os papéis dos arquitetos dentro desta conjuntura (EASTMAN et al., 2014). No processo de projeto e construção tradicional, apelidado de "over the wall", arquitetos, engenheiros, empreiteiros e a indústria de materiais de construção apenas despachavam documentos de um para o outro, mas não colaboravam de maneira efetiva. Neste contexto, devido às características de sua formação, os arquitetos têm a capacidade de promover uma maior integração entre os envolvidos no processo. Essa aproximação, por um lado, permite abordagens mais assertivas e uma maior qualidade, mas, por outro, demanda novas posturas de trabalho para alcançar esses resultados (KIERAN; TIMBERLAKE, 2003).

A aproximação da arquitetura com a indústria depende, em grande parte, de uma reformulação dos processos de projeto (KIERAN; TIMBERLAKE, 2003). Não é uma novidade que determinadas escolhas tidas como intuitivas no projeto arquitetônico podem ser sistematizadas em uma sequência de passos para sua execução, ou seja, em algoritmos (EASTMAN, 1968; MITCHELL, 1975). Diversas estratégias computacionais podem ser utilizadas com este objetivo. Uma delas é a baseada em regras, na qual ações procedurais e condicionais são estabelecidas para a execução de ações (RACEC; BUDULAN; VELLIDO, 2016; DU et al., 2020).

Este artigo faz uma aplicação desta abordagem, com o objetivo de se obter uma maior integração entre a arquitetura e a indústria durante a fase de projeto, utilizando a indústria de banheiros pré-fabricados como estudo de caso. A aplicação consistiu na implementação de algoritmos para a geração parametrizada do layout de banheiros, o qual impacta diretamente a distribuição de equipamentos, os pontos de elétrica e hidráulica, a distribuição de perfis e a sua furação para a passagem de sistemas complementares bem como para o corte das peças. Assim, informações se encontram representadas espacialmente em BIM para o projeto arquitetônico, segundo regras ideais de distribuição, e os desenhos para a fabricação são extraídos desse modelo automaticamente. A associação do BIM com algoritmos baseados em regras permite que qualquer mudança no layout acarrete uma alteração, em tempo real, de todas as demais informações do sistema, isto é, caso uma das dimensões do banheiro mude, 
por exemplo, todos os outros elementos se redistribuirão automaticamente e os desenhos de fabricação serão atualizados.

Neste artigo propõe-se que a geração automatizada de layouts associada ao BIM pode ser uma estratégia para favorecer a industrialização da arquitetura e aumentar a produtividade ainda na fase de projeto. Ele está dividido em duas seções. Na primeira delas, discorre-se sobre BIM e como essa mudança de perspectiva pode elevar o grau de maturidade de utilização do BIM bem como processos algorítmicos podem ser aplicados para a geração de layouts. Na seção seguinte, demonstra-se uma aplicação prática destes conceitos, no que diz respeito a criação de um workflow entre algoritmos, BIM e fabricação.

\section{FUNDAMENTAÇÃO TEÓRICA}

\section{DA MODELAGEM DA INFORMAÇÃO DA CONSTRUÇÃO PARA A MODELAGEM DA INFORMAÇÃO DA CONSTRUÇÃO COM O USO DE ALGORITMOS}

Uma das definições possíveis para o BIM é "uma tecnologia de modelagem e um conjunto de processos para produzir, comunicar e analisar modelos de construção" (EASTMAN et al., 2014, p. 13). Tecnologia pode ser definida como "the application of scientific knowledge for practical purposes" (OXFORD, 2007 apud Succar, 2009, p. 359) e inclui software, hardware e equipamentos para aumentar a eficiência e produtividade da AEC (SUCCAR, 2009). Por processos, Succar (2009, p. 359) caracteriza como "a specific ordering of work activities across time and place, with a beginning, an end, and clearly identified inputs and outputs: a structure for action". Além destas duas características, Succar (2009) atribui uma esfera política para o BIM que pode ser definido como "written principles or rules to guide decision-making" (CLEMSON, 2007 apud SUCCAR, 2009, p. 359).

Dentro deste contexto, para Succar (2009) existem quatro graus de maturidade associadas à utilização do BIM. Inicialmente há o pré-BIM na qual há muita dependência de informações bidimensionais para representar uma realidade tridimensional. No geral, quantidades e custos são estimados, o processo de projeto é linear, há baixo investimento tecnológico e pouca interoperabilidade. No primeiro nível de utilização do BIM há a criação de objetos parametrizados, porém de forma "unidisciplinar". Já nesta fase se consegue ter desenhos coerentes no que diz respeito a coordenação do modelo tridimensional e das vistas bidimensionais. Consolidadas esta habilidade de modelagem, a etapa 2 diz respeito ao compartilhamento do modelo com profissionais de outras áreas, proporcionando uma colaboração baseada em modelo. Por fim, a etapa 3 refere-se ao maior grau de integração e colaboração entre profissionais.

Importante destacar que a passagem de um nível de maturidade menor para outro mais elevado demanda esforços técnicos, processuais e políticos em graus diferentes. A transição do pré-BIM para o grau 1 demanda o desenvolvimento de habilidades técnicas enquanto para os níveis mais altos, habilidades processuais e políticas são requeridas devido à maior colaboração com outros profissionais de diferentes áreas. Em razão desta demanda significativa de esforços técnicos na etapa inicial, é possível uma subutilização do potencial do BIM. No desenvolvimento de projetos em escritórios de arquitetura, que é o foco deste artigo, a utilização do BIM muitas vezes é reduzida a uma produção de desenhos coerentes, isto é limitada a um menor grau de maturidade de utilização.

Mesmo que essa discussão exista atualmente sobre o BIM, ela não é recente quando ela é ampliada para a utilização de computadores na arquitetura. Mitchell (1975), por exemplo, apesar de não se referir a questão colaborativa que é tema da pesquisa de Succar (2009), também discute que existem graus de utilização de computadores no desenvolvimento de um 
projeto arquitetônico. Em um nível mais simples de utilização, os computadores seriam utilizados apenas para representação e para cálculo, similarmente ao que se fazia com uma prancheta virtual, porém em um ambiente digital. Em níveis intermediários, por sua vez, um algoritmo pode gerar diversas soluções para um problema (muitas vezes não previstas pelo projetista), em seguida os profissionais poderiam selecionar a que responde melhor a questão colocada inicialmente. Uma outra possibilidade seria os arquitetos produzirem modelos e algoritmos avaliarem o desempenho da construção, como comumente ocorre hoje com sistemas integrados de simulação estrutural e energética. Em um maior nível de utilização, por sua vez, as "máquinas" seriam capazes de analisar as decisões dos projetistas e antever soluções, isto é, ter maior autonomia.

Deste modo, dentro desta classificação descrita por Succar (2009), é possível discutir o nível de "algoritmização" de processos na arquitetura, como colocado Mitchell (1975). Apesar dos softwares BIM serem inerentemente paramétricos, o trabalho em BIM pode estar permeado de trabalhos manuais e repetitivos centrados na habilidade humana, mas que poderiam ser sistematizados e "algoritmizados". Ou seja, por uma releitura de Mitchell (1975), a utilização do BIM também pode ser reduzida a uma prancheta virtual e mesmo no grau de maturidade 1 de utilização do BIM (SUCCAR, 2009) há poucos processos automatizados. Essa carência de automatização pode comprometer a assertividade do trabalho e consequentemente aumentar o custo e tempo de desenvolvimento do projeto, pela redução da produtividade. Assim, mais do que utilizar o BIM como uma ferramenta de modelagem de informação, poder-se-ia otimizar processos por meio de algoritmos. Essa atuação sobre processos pode ocorrer desde os graus iniciais de utilização de BIM até os mais altos. Entretanto, ela pode ser uma estratégia fundamental para a passagem de graus mais baixos de maturidade para maiores.

O projeto do algoritmo pode ser associado ao BIM para geração, otimização, análise e fabricação. Eastman et al. (2014) afirmam que o BIM permite que arquitetos e engenheiros realizem simulações e análises já em estágios iniciais de projeto. 0 desenvolvimento de algoritmos e sua integração com um sistema paramétrico favoreceria esses mecanismos de avaliação. Desta forma, há uma exploração de possibilidades e uma convergência para as melhores soluções. Bianconi, Filippucci e Buffi (2019), por exemplo, desenvolveram um sistema gerador para a obtenção de residências com melhor desempenho térmico. Da mesma forma, Wahbeh (2017) explora a conexão entre algoritmos e o BIM para o desenvolvimento de fachadas. Além disso, Veloso, Celani e Scheeren (2018) propuseram a geração automatizada de layouts de apartamentos combinando BIM e uma gramática da forma.

Mesmo que a atuação dos arquitetos seja estratégica dentro de um empreendimento consolidado em BIM, a atenção à otimização de processos por meio de algoritmos não é amplamente difundida. Inclusive, a não automatização de etapas pode inviabilizar um avanço para uma maior maturidade em razão dos custos associados a trabalhos repetitivos.

\section{GERAÇÃO DE LAYOUTS COM BASE EM REGRAS}

Diversas estratégias são encontradas na literatura para geração automática de layouts. Uma categorização de procedimentos para a automatização de layouts é realizada por Du et at. (2020) por meio de uma revisão da literatura. Os autores englobam geração de espaços e de layouts de mobiliário, apresentando uma rica discussão para classificação de métodos. Du et at. (2020) trabalham com as seguintes classificações para geração de layouts automatizados: baseada em forças físicas (Arvin; House, 2002); teoria dos grafos (BIAGINI; DONATO; PELLIS, 2015; FU et al., 2017; WONG E CHAN, 2009); atribuição de célula (DINO, 2016; LOPES et al. 2020); divisão espacial (DAS et al., 2020; KNECHT; KOENIG, 2010; CORREIA; DUARTE; LEITÃO, 2012; KOENIG; KNECHT, 2014; ABDELMOHSEN; ASSEM; TARABISHY, 2016); baseada em 
agentes (GHAFFARIAN; FALLAH; JACOB, 2018, CHANG, 2018); aprendizado de máquina (AS; PAL; BASU, 2020; CHAILLOU, 2019) e programação matemática.

No caso da programação matemática, ou baseada em regras, os parâmetros relativos ao layout são explicitados em fórmulas matemáticas. A localização dos elementos é representada por coordenadas e as restrições espaciais são traduzidas em variáveis dentro de equações a fim de evitar sobreposição ou obstrução de passagem. Essa possibilidade de construção de funções matemáticas, por exemplo, abre caminhos para a aplicação de algoritmos evolutivos na resolução de layouts (CALIXTO, 2016; DU et al., 2020; MICHALEK; CHOUDHARY; PAPALAMBROS, 2002).

Du et al. (2020) analisa sessenta e seis artigos e os classifica dentro dessas sete categorias. Em seguida, faz uma análise do processo de automatização de cada metodologia. 0 autor analisa (1) a viabilidade, considerando requisitos para uma aplicação prática; (2) a usabilidade, analisando se o processo é facilmente controlado pelo usuário; (3) a velocidade de geração, quão rápido se pode chegar a uma solução por este método; (4) a variação, quão fácil é gerar diferentes soluções; (5) a capacidade de trabalho com maior número de edifícios com mais de um pavimento; (6) a capacidade de trabalhar com espaços não retangulares e, por fim, (7) a necessidade da existência de limites pré-estabelecidos. Os parâmetros de variação, trabalho com diferentes níveis, capacidade de trabalhar com formas não retangulares e existência ou não de limites pré-definidos foram classificados como quantitativos. Assim, Du et al. (2020) classifica as metodologias segundo a força de cada uma dentro desses critérios com base nos sessenta e seis artigos coletados.

Du et al. (2020) destacam que mudanças geométricas são mais fáceis de serem realizadas através de um modelo de programação matemática. Entretanto, os autores apontam que mais operações são necessárias quando se pretende realizar mudanças topológicas, como rotação, espelhamento e alterações de dimensões. 0 aprendizado de máquina, por sua vez, se mostra como um método com alto potencial para gerar espaços com formas irregulares a partir da leitura de um grande conjunto de dados. Entretanto, afirmam também que pode existir a combinação entre métodos, como de programação matemática e de divisão, para solucionar ambientes com formas irregulares.

É possível inferir que a mudança da posição e de dimensões de mobiliários durante o processo de geração de layouts de mobiliários poderiam ser facilitadas por meio da metodologia de programação matemática. E, se associadas com outras metodologias, estas poderiam alcançar melhores resultados. Du et al. (2020) não pontuam a associação destas metodologias com o BIM. Entretanto, devido a sua natureza paramétrica e a facilidade de se acessar e modificar parâmetros, sua utilização poderia potencializar os processos dentro de cada uma delas.

Esse aumento de produtividade devido a implementação de algoritmos baseado em regras em BIM pode ser visto no trabalho de Anderson et al. (2018), que desenvolvem um sistema de geração automatizada de layouts para salas privadas de trabalho da WeWork. Os algoritmos desenvolvidos foram comparados com 13000 layouts de salas comerciais desenvolvidos manualmente por arquitetos. Os autores descrevem que em $77 \%$ dos casos o algoritmo teve um desempenho igual àqueles feitos por arquitetos, sendo que se houvesse um relaxamento na interpretação este número poderia chegar a 97\%, e em $6 \%$ o desempenho foi superior. Anderson et al. (2018) apresentam algumas diretrizes para a interface em oposição a um sistema totalmente automatizado, mas que favoreça a produtividade e um ambiente flexível.

O trabalho de Anderson et al. (2018) traz uma importante contribuição tanto pela metodologia incremental desenvolvida como pelos resultados obtidos. Os autores demonstram a possibilidade de sistematizar tarefas repetitivas como meio para potencializar o processo criativo dos arquitetos. Ao mesmo tempo, demonstram que um algoritmo de geração de layouts 
pode alcançar resultados iguais ou melhores que os produzidos manualmente por arquitetos. Neste caso, há uma clara divisão de tarefas entre projetistas e máquinas, segundo o que cada um pode desenvolver de melhor.

Neste artigo, por sua vez, busca-se aliar a geração automatizada em BIM para diminuir retrabalhos em sistemas em que há um conjunto claro de restrições e de produtos como ocorre na indústria de banheiros pré-fabricados.

\section{METODOLOGIA}

Uma metodologia exploratória e incremental foi utilizada nesta pesquisa com objetivo de reduzir trabalhos manuais e repetivos em BIM, sendo que a indústria de banheiros préfabricados foi escolhida como base empírica para a experimentação. Conforme observado na literatura, ela possui características desejáveis para a automação, tais como: (1) ser um sistema que pode ser analisado independentemente do restante do edifício, (2) ser um caminho crítico no cronograma de construção, e (3) conter arquitetura, sistemas elétricos, hidráulicos e estruturais em um pequeno espaço. Embora algumas indústrias do setor já estejam começando a utilizar o BIM e alguma automação no processo produtivo (por exemplo, com equipamentos CNC para corte de gesso acartonado ou furação de perfis metálicos), não há evidências do uso de automação no processo de projeto, como descrito anteriormente. Isto é, transitam entre o pré-BIM e o BIM de grau 1. Em geral, eles ainda são incapazes de produzir projetos personalizados únicos, sendo necessária a produção de pelo menos algumas dezenas de unidades idênticas. Assim, partindo da identificação de regras que permeiam o projeto de banheiros pré-fabricados e criando automatizações estratégicas, haveria um aumento na produtividade de fabricação e, por consequência, um aumento na personalização em massa da indústria.

Figura 1. Inicialmente, três tipologias foram trabalhadas.

Porém, como prova de conceito, a tipologia 1 foi escolhida para as próximas etapas.

Fonte: Elaborado pelos autores

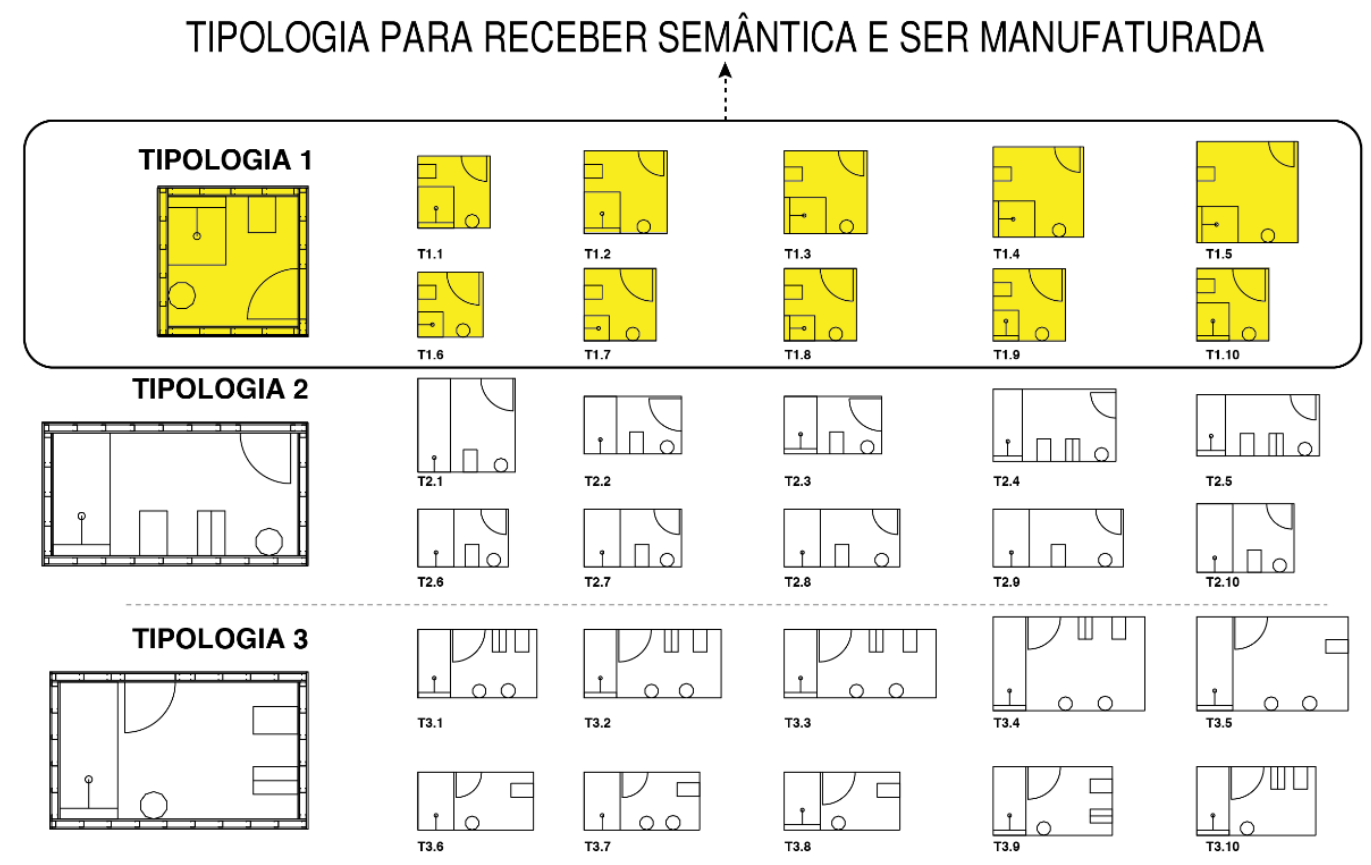

Para esta pesquisa, foi adotada uma tipologia genérica de banheiro quadrado (figura 1) que poderia integrar o catálogo de uma indústria do setor. 0 fluxo de trabalho entre o projeto algorítmico e o BIM foi desenvolvido de forma incremental por meio da programação visual e textual no Grasshopper e o VisualArq, uma plataforma que permite a interoperabilidade entre 
o projeto algorítmico e o BIM. É importante destacar que a programação visual permite a criação de algoritmos para profissionais que não estão familiarizados com a programação textual, tornando o código acessível para manutenção e novas implementações, como é comum entre os arquitetos (PREIDEL; BORRMANN, 2016).

O algoritmo desenvolvido é iniciado pela definição das variáveis e pela sua valoração. $\mathrm{Na}$ sequência, as geometrias resultantes da primeira fase recebem a semântica BIM, e qualquer alteração nas variáveis iniciais resulta em uma alteração automática das informações atribuídas. Esta associação foi possível através do VisualArq, um plugin para Rhinoceros e Grasshopper que permite trabalhar com BIM. Especificamente, dentro do Grasshopper, o VisualArq possui componentes (métodos) que podem ser integrados no algoritmo. Eles representam diferentes categorias semânticas pertencentes a construção, como parede, parede cortina, viga, coluna, porta, janela, abertura, escada, guarda-corpo etc. Em geral, cada uma dessas categorias tem componentes semelhantes para criar, atribuir informações e aplicar tipologias, bem como desconstruir cada elemento e analisar informações associadas ao modelo. Assim, por um lado, é possível construir a semântica BIM e, por outro, usar rapidamente as informações paramétricas aninhadas nos elementos (Figura 2).

Esse processo de desconstrução permitiu a geração de desenhos para fabricação, pois os componentes de cada elemento construtivo podem ser facilmente extraídos e manipulados, isto é, planificados e colocados, lado a lado, no plano horizontal. Este procedimento permite que as peças sejam cortadas por máquinas de controle numérico. As seções a seguir detalham esse procedimento (Figura 3).

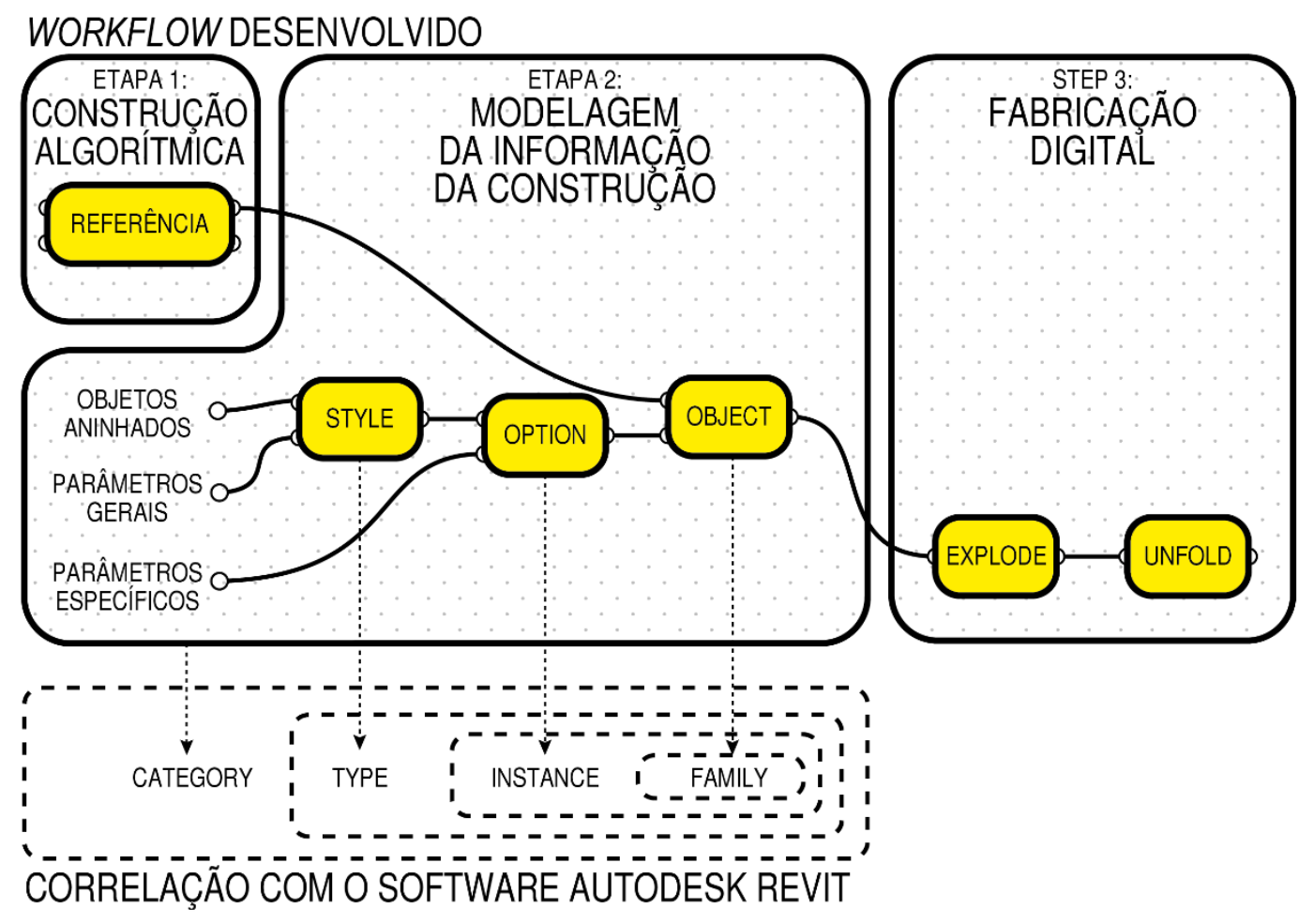

Figura 2. Etapas do procedimento proposto e a sua construção semântica realizada no ambiente do Grasshopper em relação a estruturação do Revit, outro software de modelagem BIM.

Fonte: Elaborado pelos autores 
Figura 3. Workflow desenvolvido baseado em

regras que permite a construção de semântica e a

sua desconstrução para fabricação.

Fonte: Elaborado pelos autores

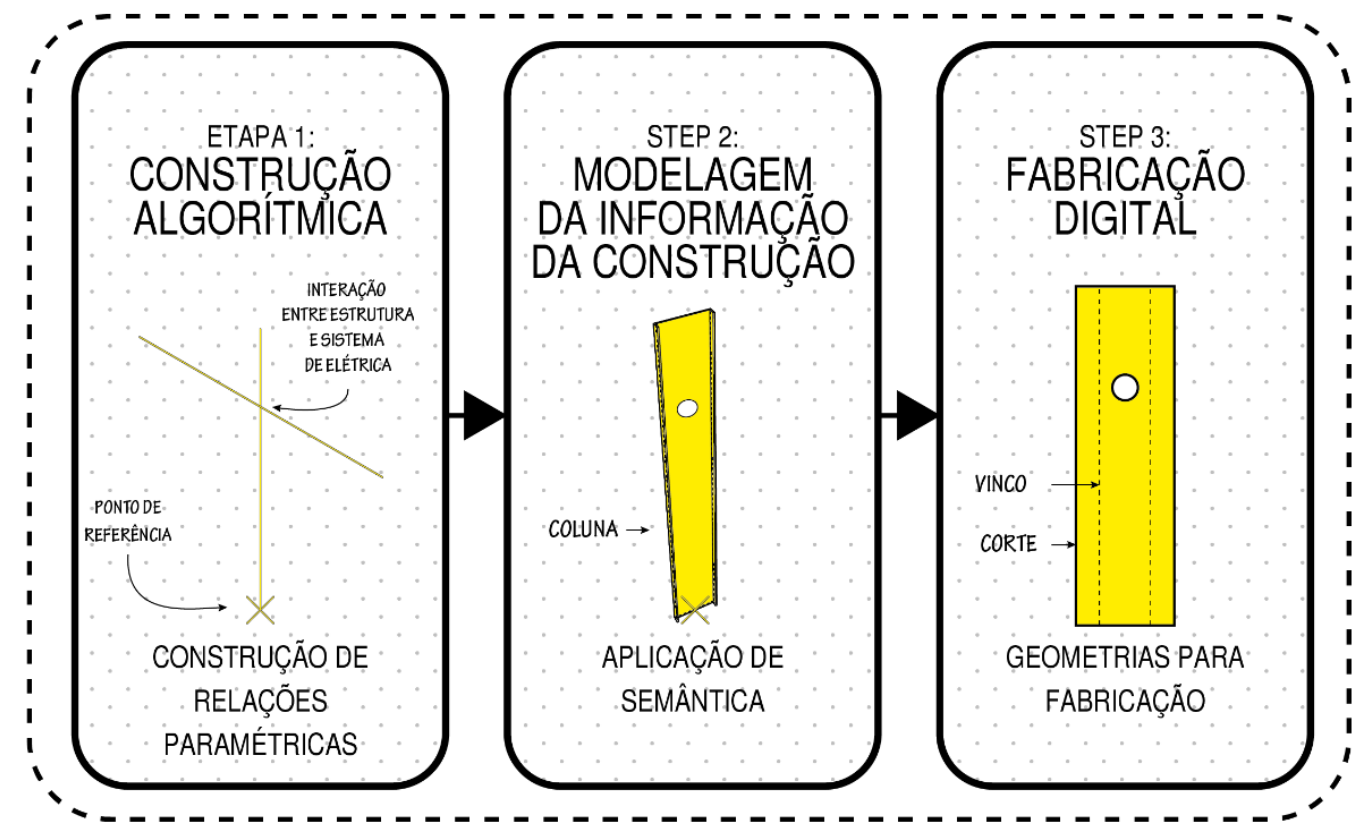

\section{ETAPAS DE IMPLEMENTAÇÃO}

Neste artigo, um banheiro de planta quadrada foi utilizado como estudo de caso a partir de uma visão sistêmica de seus elementos constituintes (layout, estrutura, painéis de parede e forro). Os subsistemas recebiam os valores das variáveis iniciais e, após a execução das operações, devolviam os resultados ao algoritmo principal. Essa metodologia permitiu a compreensão de um problema complexo por meio do reconhecimento de suas partes menores e suas regras projetuais intuitivas. Desde o início, porém, o impacto de cada parte com o todo foi considerado na distribuição das variáveis ao longo do algoritmo. A implementação foi estruturada em (1) valoração das variáveis, (2) atribuição de semântica e (3) extração de desenho para fabricação. Na sequência apresenta-se o procedimento detalhado da implementação com objetivo de evidenciar as relações de construção e desconstrução semântica.

\section{VALORAÇÃO DAS VARIÁVEIS}

O algoritmo partiu da valoração das variáveis, por meio de estratégias que permitissem que o usuário escolhesse valores dentro de intervalos pré-determinados como aceitáveis. Por exemplo, a largura do banheiro poderia receber valores de 2,2m, 2,4m, 2,6. 2,8m e $3 \mathrm{~m}$ já o layout pode incluiria uma ou duas pias. No caso do ambiente de programação visual do Grasshopper, as variáveis podem ser inseridas por meio de diferentes interfaces, como controles deslizantes numéricos, painéis, métodos de verdadeiro ou falso, listas de valores, entre outros. A Figura 4 ilustra este fluxo por subsistema e a Figura 5 as diferentes propostas possíveis.

Observou-se que, ao colocar mais variáveis no início do algoritmo e menos ao longo dele, a parametrização do programa foi facilitada, criando interdependência entre seus subsistemas. Além disso, as operações matemáticas necessárias eram realizadas com as variáveis também neste momento. Os valores obtidos foram indexados de forma a facilitar o controle das informações e futuras manutenções. Cada subsistema do algoritmo seguiu esta estruturação: 
entradas indexadas formando listas de informações que expressam todo o conjunto do sistema, em seguida filtragem das informações sejam elas numéricas ou geométricas e aplicação das informações em novos subsistemas.
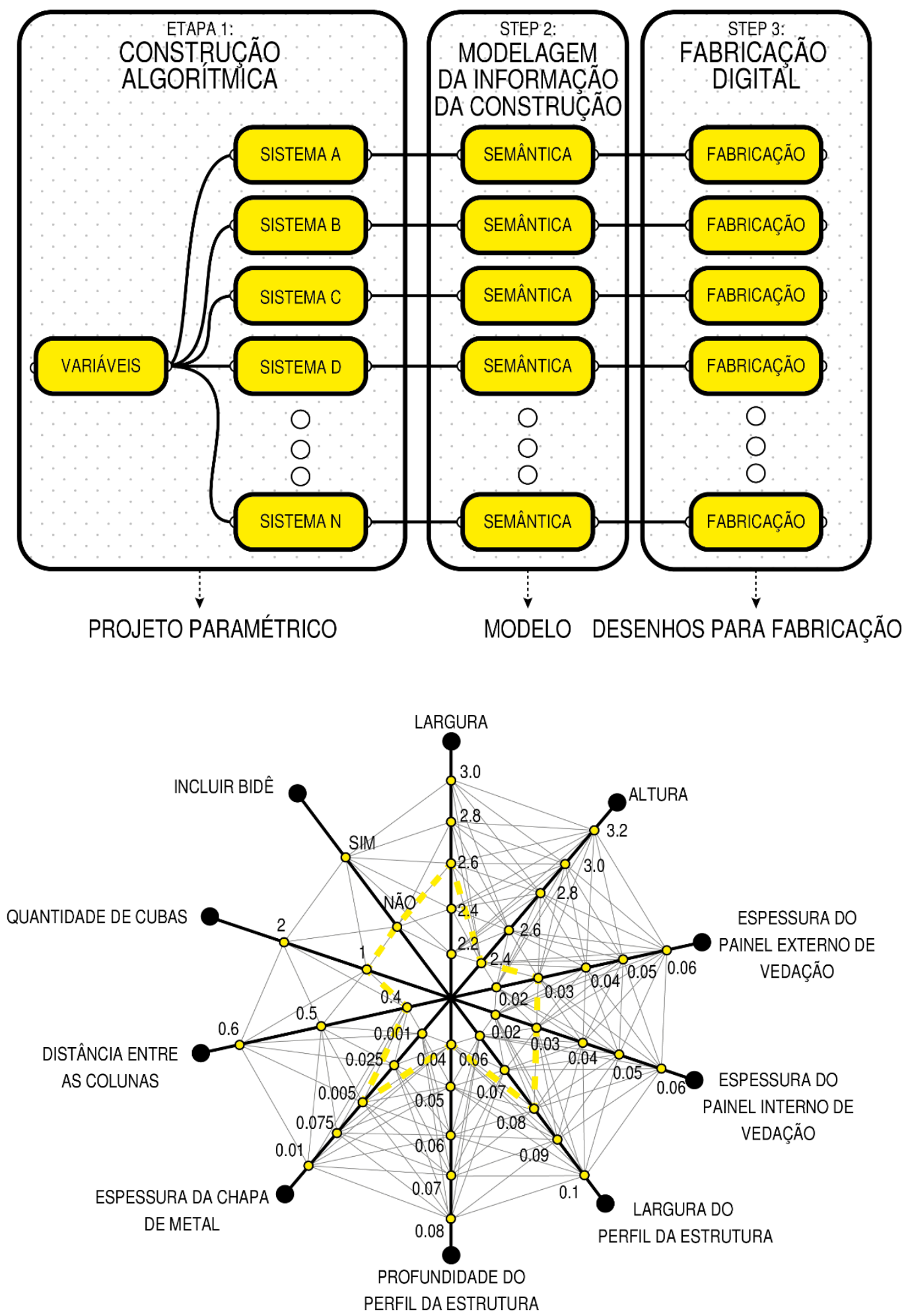

Figura 4. Fluxo da informação dividida em três etapas: processo algorítmico, aplicação de semântica e fabricação.

Fonte: Elaborado pelos autores

Figura 5. Variação e possíveis combinações.

Fonte: Elaborado pelos autores 


\section{CONSTRUÇÃO DAS GEOMETRIAS DE REFERÊNCIA}

\section{Curvas de perímetro}

Inicialmente, determinadas variáveis foram utilizadas para criar retângulos, que depois serviram como base para outros processos nas etapas seguintes. Isto é, curvas que marcam o posicionamento dos painéis internos e externos das paredes bem como as curvas de referência para a estrutura, da base de concreto, do forro e do layout. No mesmo pacote de dados retornaram ao sistema variáveis numéricas como a espessura total das paredes e as regras matemáticas que foram construídas no início do algoritmo principal.

\section{Layout}

O layout foi construído em paralelo ao subsistema de geração das curvas de perímetro, sendo o desenvolvimento feito em Python. As entradas criadas receberam variáveis com valores dimensionais (como largura e comprimento do banheiro, altura do forro, espessura da parede e distância entre o canto da parede e o ponto de inserção da porta) e valores condicionais (se a porta está na frente ou na lateral, se há uma ou duas pias e se há um bidê ou não). Dependendo da combinação de variáveis, o layout seria organizado de maneiras diferentes. Nesta ocasião, foi implementado o layout de um banheiro quadrado com pia, vaso sanitário, shaft e chuveiro.

\section{Estrutura}

O código para a estrutura foi inicializado recebendo os parâmetros das curvas de perímetro. A curva do eixo central da estrutura foi desconstruída, resultando em quatro delas, uma para cada parede. Cada uma teve sua dimensão ajustada, de acordo com os parâmetros de entrada relacionados à espessura dos painéis internos e externos. Nesse momento, cada uma das curvas já estava indexada, possibilitando melhor organização e controle do código nas etapas seguintes.

Posteriormente, cada curva recebeu pontos para a inserção dos montantes verticais da estrutura de aço leve galvanizado (pilares). 0 algoritmo permite a divisão da parede de cada módulo de diferentes maneiras: (1) segmentos iguais, com o tamanho do primeiro ou último diferente dos demais, (2) segmentos iguais, com o restante da divisão dividido igualmente entre os primeiros e últimos segmentos e (3) todos os segmentos com a mesma dimensão. Este mecanismo permite uma mudança rápida na distribuição dos perfis, proporcionando ao fabricante um maior controle do processo produtivo.

A lista estruturada de pontos foi bifurcada e aqueles pertencentes à curva mais do canto do retângulo inicial foram trabalhados separadamente para inserção da porta. Os pontos relativos aos batentes foram adicionados à lista de pontos pertencentes à estrutura e os que ficaram no vão da porta foram removidos por meio de condicionais. Por fim, os perfis horizontais da estrutura (vigas) foram adicionados e todos os subsistemas foram reunidos novamente em uma única lista de dados. Os resultados podem ser vistos na Figura 6. 


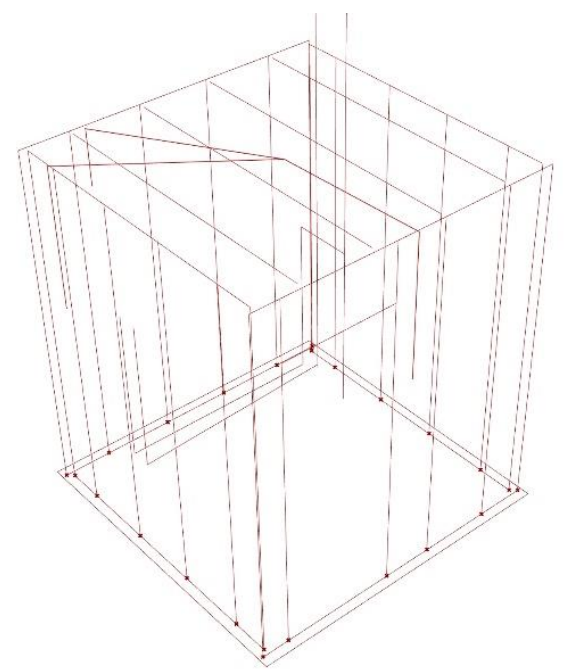

Figura 6. Geometrias base antes de receber semântica.

Fonte: Elaborado pelos autores

\section{Portas, painéis internos e externos}

Os algoritmos para os painéis internos e externos foram estruturados de forma semelhante. Os sistemas receberam os conjuntos de curvas e os pontos de inserção dos montantes. Cada ponto foi usado como origem de um plano de referência. Em seguida, os pontos de interseção entre os planos e as curvas foram encontrados. Cada uma delas foi inicialmente utilizada para criar linhas, que depois foram desconstruídas, retornando diversos segmentos de linha que serviram de base para a colocação dos painéis. Assim, a junção dos painéis sempre seria colocada no ponto médio dos montantes.

A porta foi implementada a partir do ponto de origem cartesiana do layout. Dado o devido espaçamento entre a porta e a parede lateral, uma caixa central foi criada para que houvesse um vão de $800 \times 2100 \mathrm{~mm}$ (outras dimensões poderiam ser atribuídas).

\section{Paginação de piso}

O piso cerâmico foi implementado no algoritmo de modo que as suas dimensões pudessem ser variadas pelo usuário. 0 código recebeu as curvas de referência referentes ao perímetro interno do banheiro e, após algumas operações, foi utilizado um dos pontos extremos de uma das curvas que está próximo da porta como ponto de origem. Com esta base, criou-se um retângulo na medida da peça cerâmica desejada que seria repetida inúmeras vezes ao longo da largura e do comprimento do banheiro. Na sequência, estas geometrias foram cortadas, primeiramente pelo perímetro interno do banheiro e depois pela projeção de onde estava o box do banheiro. Este procedimento foi empregado, pois a modulação das peças nem sempre se adequa às dimensões do ambiente, fazendo-se necessário cortar algumas peças. Como é de praxe, o ponto de referência da paginação do piso se encontra próximo à porta e os recortes acontecem nos extremos opostos (relações que podem ser alteradas caso necessário).

\section{Forro}

Mais do que a obtenção de geometrias, o algoritmo procurou uma melhor distribuição das placas do forro a fim de reduzir desperdícios e quantidade de cortes. Pelas dimensões máximas das placas de gesso acartonado serem no máximo de 1200x2400mm, caso o banheiro tivesse dimensões internas menores ou iguais que $2400 \times 2400 \mathrm{~mm}$ seriam usadas duas placas de iguais dimensões. Entretanto, se fosse diferente seria acrescentada mais uma fileira de painéis, inclusive já de forma intercalada de modo que cada painel se encaixasse alternadamente com o outro ao lado. Para tanto, uma condicional em Python foi implementada para análise dos 
valores de dimensão de entrada além de outros mecanismos para trabalhar e organizar os itens das listas estruturadas do algoritmo principal.

\section{Elétrica e hidráulica}

Três passos foram considerados na implementação dos sistemas de elétrica e hidráulica: (1) posicionamento, (2) conflito com outros sistemas e (3) corte da estrutura e vedação. Pontos de tomada e de iluminação foram estabelecidos preliminarmente ao redor nas paredes e forro do banheiro segundo suas dimensões e dos equipamentos inseridos. Porém, dependendo do arranjo da estrutura, os montantes poderiam coincidir com os pontos de elétrica. Assim, para resolver essa questão foi necessário utilizar uma condicional em Python segundo a qual, caso houvesse conflito, o ponto de elétrica seria levemente deslocado na horizontal. Um looping foi implementado de modo que o código avaliasse as coordenadas de cada um dos pilares relativos à parede onde estava o ponto de elétrica. Caso algum destes valores coincidisse com as coordenadas desse ponto, o looping pararia e retornaria um valor de deslocamento; caso contrário, os valores anteriores permaneceriam. A última etapa foi verificar onde os painéis, pilares e vigas deveriam ser furados. Para obtenção dessas relações, um caminho hipotético de conduítes foi desenvolvido e sólidos foram gerados na espessura desejada para os furos que serviram para o corte das peças. 0 mesmo foi feito para os pontos de inserção.

A parametrização da hidráulica foi dividida em sistemas de água fria e esgoto. No primeiro caso, partiu-se verticalmente do ponto referente à cuba até outro um pouco acima do piso. Em seguida, a linha seguiu na horizontal passando por baixo do gabinete e do piso elevado do box até chegar ao shaft. Por meio da construção de intersecções entre planos e linhas, a linha que representa o ramal da cuba se encontra automaticamente com a coluna de água do shaft. É importante ressaltar que este procedimento só se aplica nos casos em que o lavatório se encontra ao lado do box. Caso isso não ocorresse, a tubulação teria que ser embutida na parede. O mesmo procedimento foi realizado para a tubulação de esgoto do lavatório. Nesse caso, porém, o código dá a inclinação da tubulação horizontal segundo as distâncias entre as tubulações verticais. No caso do esgoto do sanitário, que possui saída horizontal, é necessário fazer um engrossamento da parede para encaminhar a tubulação até o shaft.

\section{APLICAÇÃO DE SEMÂNTICA}

Cada um dos sistemas apresentados anteriormente, com exceção do layout e sistemas complementares, recebeu uma informação semântica nesta etapa. Isto é, foi feita uma associação de cada objeto com elementos construtivos em BIM. Isso poderia acontecer por muitos caminhos (CÔCO JÚNIOR E CELANI, 2018). Entretanto, o VisualArq se mostrou uma boa opção para a proposta da pesquisa, por possuir grande interoperabilidade com ambientes de programação.

A sequência lógica de construção do código foi de parâmetros mais gerais até os mais específicos. Por exemplo: o algoritmo foi iniciado com o componente do VisualArq chamado Style que continha parâmetros comuns às opções dos objetos, que por sua vez atribuíam informações a um ou mais elementos. Outras estruturas poderiam estar associadas na continuidade, como operações booleanas ou a criação de novos parâmetros. As peças receberam um código de identificação que auxiliou na identificação na etapa seguinte de prototipagem. Ao final, o modelo do banheiro modular pôde ser exportado em IFC.

\section{Estrutura}

A estrutura foi dividida em montantes do canto, montantes das paredes laterais e perfis horizontais (Figura 7). A divisão dos montantes em duas listas de dados foi necessária por diferenças de alinhamento e rotação dos elementos. Os pontos de inserção dos pilares foram 
inseridos no componente de objeto, as transformações (alinhamento e rotação) nas opções do objeto, a altura e o tipo de perfil no Style. Para os perfis horizontais também foi necessária a estruturação dos dados, haja vista as diferentes orientações e alinhamentos possíveis como, por exemplo, entre as vigas da base, do topo e sustentação do forro. Para a inserção dos perfis horizontais se demandou curvas de referência para serem inseridas no objeto. Para simplificação do código, o mesmo tipo de perfil de seção foi adotado para todos os casos.
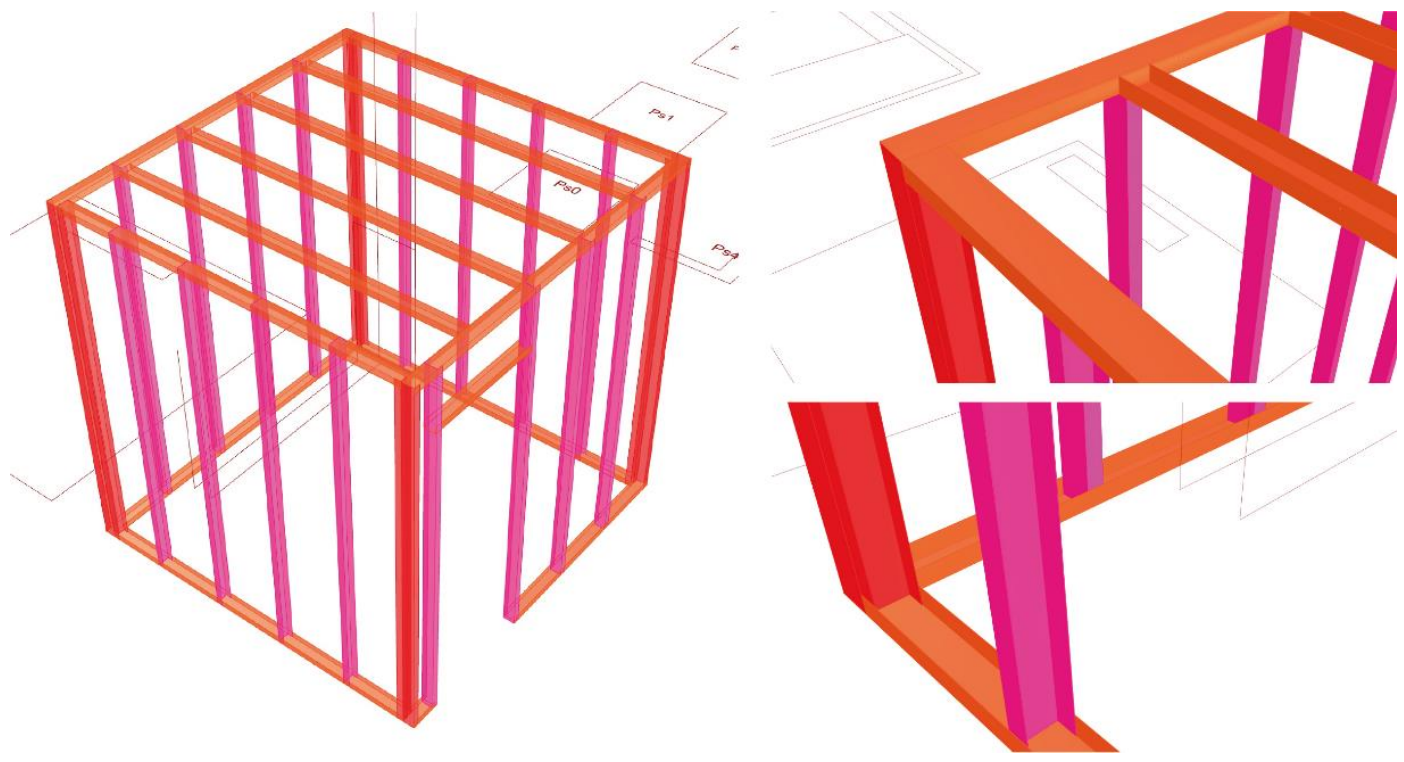

\section{Painéis internos e externos}

Os algoritmos foram similares tanto para os painéis externos quanto internos, sendo que componentes de paredes foram usados para criá-los. 0 componente de objeto recebeu uma curva base, enquanto o componente de opções do objeto recebeu o componente Style pelo qual foi possível atribuir o parâmetro de altura. 0 alinhamento em todas as paredes ocorreu pelo centro, o que permitiu um código mais enxuto. Outra questão importante foi o fato de a curva de entrada ser composta por diversos segmentos de curva, fazendo com que houvesse uma modulação nas medidas do drywall. Ao final, o sólido referente à porta foi subtraído dos painéis e códigos de identificação foram atribuídos a cada um deles, por meio de um algoritmo em Python.

\section{Porta}

Programas BIM seguem a lógica construtiva real. Assim, uma porta sempre deve ser inserida em uma parede. No caso do algoritmo desenvolvido, seria impossível inserir a porta no sistema. Isso porque a largura e a posição da porta não necessariamente estariam de acordo com a modulação dos painéis, o que implicaria que a porta tivesse dois painéis hospedeiros e não um. Para solucionar esta questão, o vão da porta recebeu uma "parede temporária", cujas dimensões estavam alinhadas com o conjunto e nesta parede foi inserida a porta.

Os componentes de abertura do VisualArq permitiram uma grande personalização de elementos. Enquanto o componente de objeto de porta recebeu a parede hospedeira e o ponto de inserção, o componente Style recebeu as partes que existem em uma porta desejada, como a folha e o batente.

\section{Piso e forro}

O piso do banheiro pré-fabricado estudado é constituído por uma base de concreto, seguida de uma camada impermeabilizante e outra de piso cerâmico. Dado o layout descrito na fase
Figura 7. Estrutura com aplicação de semântica BIM.

Fonte: Elaborado pelos autores 
anterior, as curvas relativas aos azulejos adquiriram uma semântica construtiva, que culminou no acréscimo de espessura a esses elementos. Ao mesmo tempo em que o piso cerâmico foi adicionado ao modelo BIM, uma operação subtrativa booleana foi realizada na base de concreto.

A mesma lógica foi usada para implementação do forro. No início, o sistema recebeu sólidos com as dimensões do eixo hidráulico e dos dutos elétricos e, posteriormente, essas geometrias foram removidas dos painéis por uma operação de subtração. Com isso, o forro passou a apresentar os ajustes necessários em relação aos demais sistemas, evitando conflitos.

Portanto, nesses processos, os dados foram usados com dois propósitos para configurar a linguagem semântica do conjunto e para realizar operações de subtração sobre outras geometrias.

\section{EXTRAÇÃO DE DESENHOS PARA FABRICAÇÃO}

A última etapa do algoritmo foi extrair desenhos para fabricação. Enquanto o BIM permitiu a automatização da geração da documentação do projeto mediante extração em tempo real de desenhos bidimensionais e tabelas a partir do modelo geométrico digital, esta etapa possibilitou a extração informações para a fabricação. Assim, o modelo geométrico foi desconstruído a fim de obter desenhos para fabricação (Figura 8 e Figura 9).

Figura 8. Extração de desenhos para a fabricação.

(1) painéis externos, (2) montantes verticais e

horizontais, (3) painéis internos, (4) base de concreto,

(5) pisos cerâmicos, (6) equipamentos e shaft, (7) montantes do forro, (8) placas do forro, (9) conduítes.

Fonte: Elaborado pelos autores

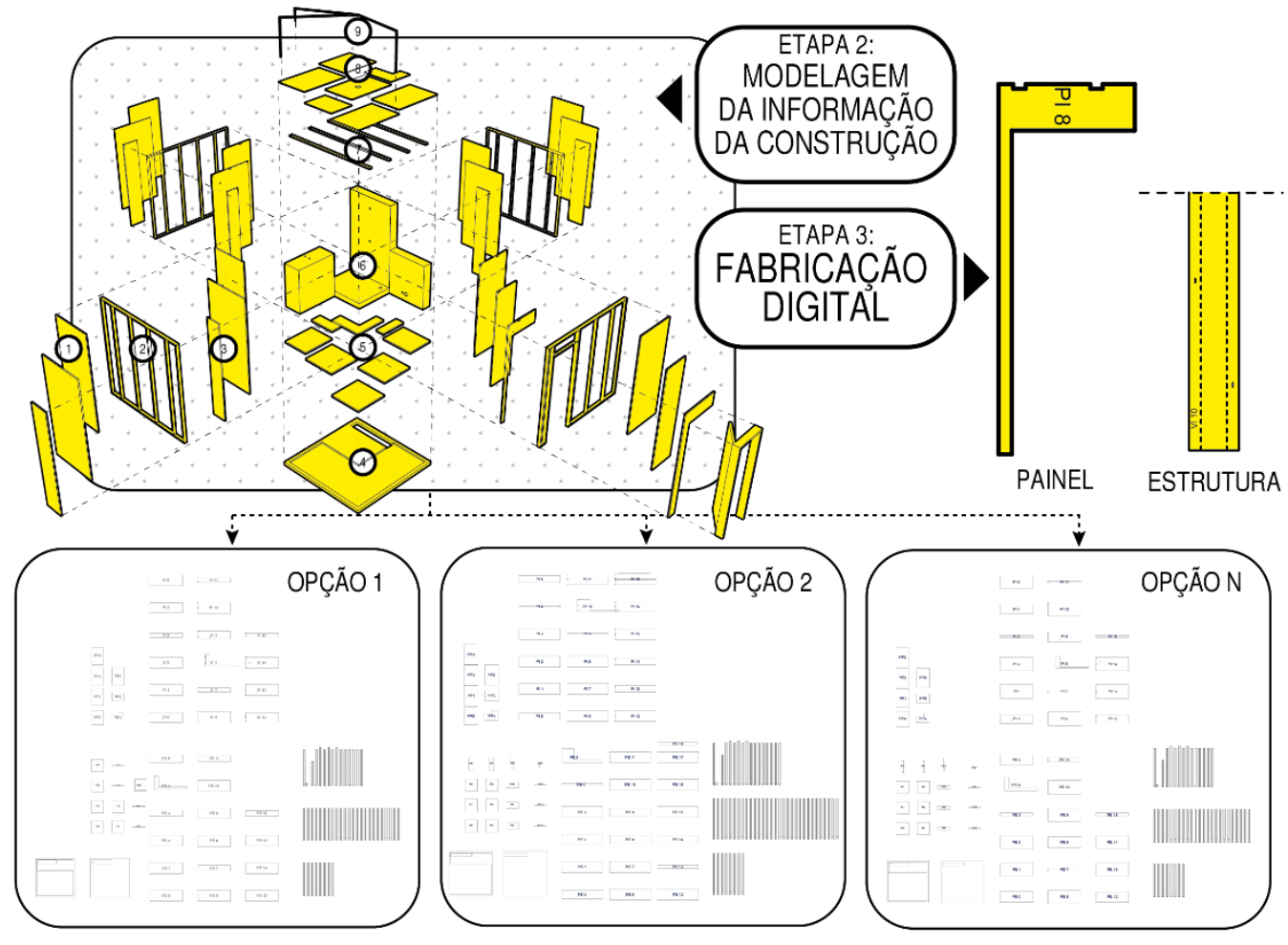

\section{Estrutura}

Os montantes verticais e horizontais deixaram de serem elementos construtivos e passaram a ser sólidos (boundary representations) por meio do componente VisualArq Explode. Em seguida, as três faces externas principais foram selecionadas e desdobradas por meio do componente Unfold pertencente ao Add-on TT Box. Neste momento as peças foram dispostas uma ao lado da outra. Novas operações foram feitas para selecionar somente as arestas, retirar as que estavam duplicadas e inserir o código relativo a cada montante. 


\section{Painéis internos e externos}

Cada um dos painéis foi tratado individualmente, movido para uma determinada posição em um grid, rotacionado uma ou mais vezes (dependendo da sua posição original) e, por último, segundo a intersecção com o plano horizontal, foram extraídas suas linhas de contorno. Ao final, foram acrescentados os nomes de identificação e algumas cotas.

\section{Piso cerâmico e forro}

Em ambos os sistemas as geometrias em BIM foram explodidas, de modo que foi possível extrair as curvas de contorno e movê-las para um determinado ponto em um grid. Elas recebem cotas e a nomenclatura padrão.

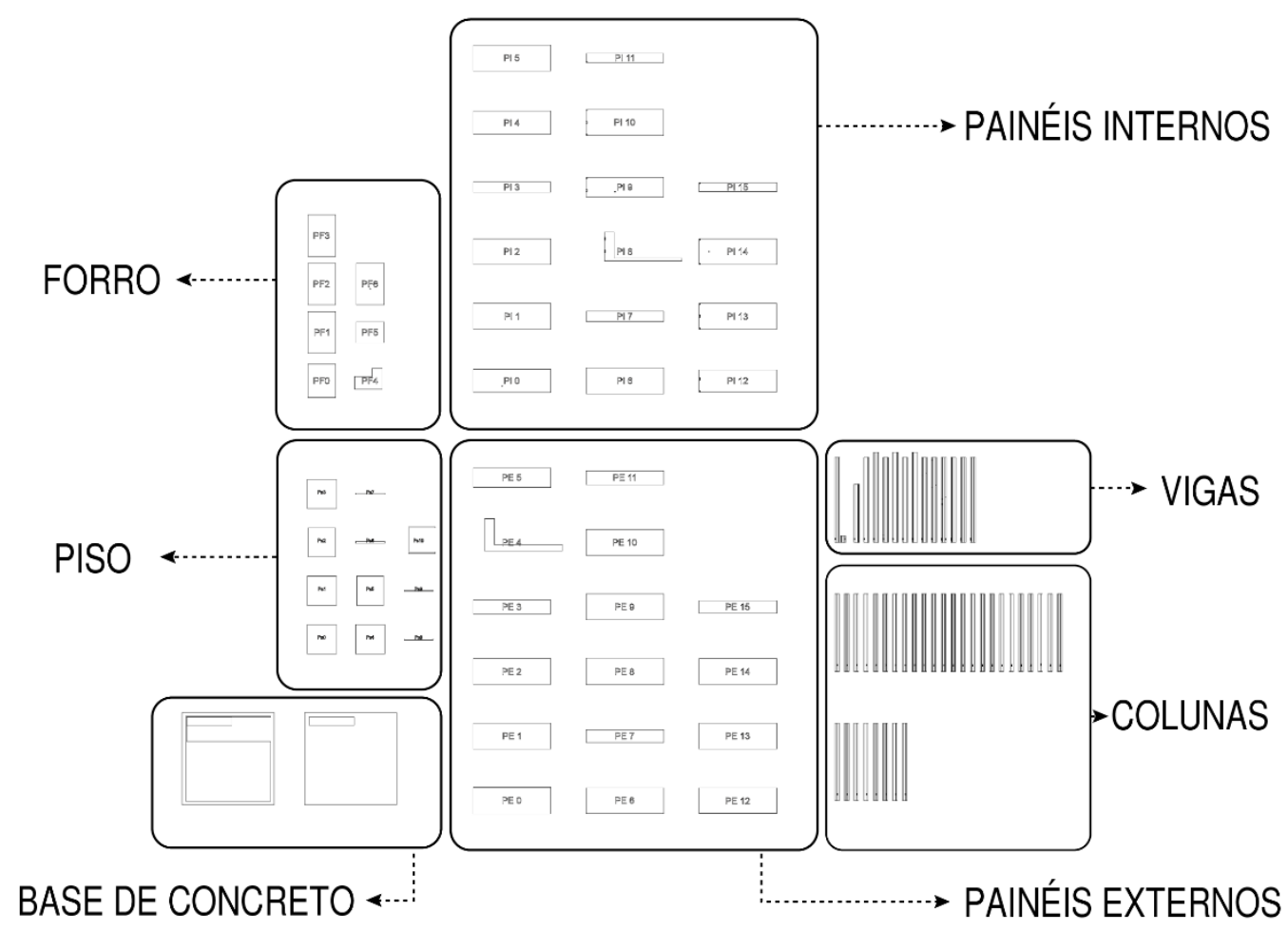

Figura 9. Peças planificadas prontas para corte.

Fonte: Elaborado pelos autores

\section{RESULTADOS E DISCUSSÃO}

Neste artigo, a modelagem algorítmica inicial permitiu que nos concentrássemos nas relações paramétricas antes mesmo de trabalhar com a semântica construtiva. Nas etapas subsequentes, a aplicação da semântica BIM otimizou o trabalho, permitindo extrair automaticamente documentos de construção e gerar e organizar informações para a produção (Figura 10).

Associado a isso, a aplicação de algoritmos - desde a geração do layout arquitetônico até o posicionamento dos montantes na estrutura, no layout do forro e do piso - trouxe grande benefício para o processo de projeto. 0 workflow desenvolvido permitiu um maior foco sobre os processos, resultando numa maior racionalização, ou seja, determinadas decisões intuitivas foram traduzidas em regras e implementadas em algoritmos. A automação de processos permitiu a rápida exploração de alternativas dentro de intervalos predeterminados como aceitáveis, bem como a atualização automática de desenhos, um dos maiores desafios na integração entre arquitetos e fabricantes (Eastman et al. 2014). 0 resultado não é apenas o 
projeto de um único banheiro, mas uma ferramenta que permite a instanciação de uma infinidade de alternativas dentro dos critérios iniciais. Após a implementação do algoritmo apresentado, uma infinidade de projetos diferentes poderia ter sua documentação completa produzida em questão de segundos. Conforme colocado por Eastman et al. (2014), a atualização automática de projetos é uma das principais vantagens da implementação do BIM para os fabricantes.

Figura 10. Resultado com modelo BIM e peças para corte. Tanto o modelo quanto os desenhos são atualizados em tempo real mediante a valoração das variáveis.

Fonte: Elaborado pelos autores
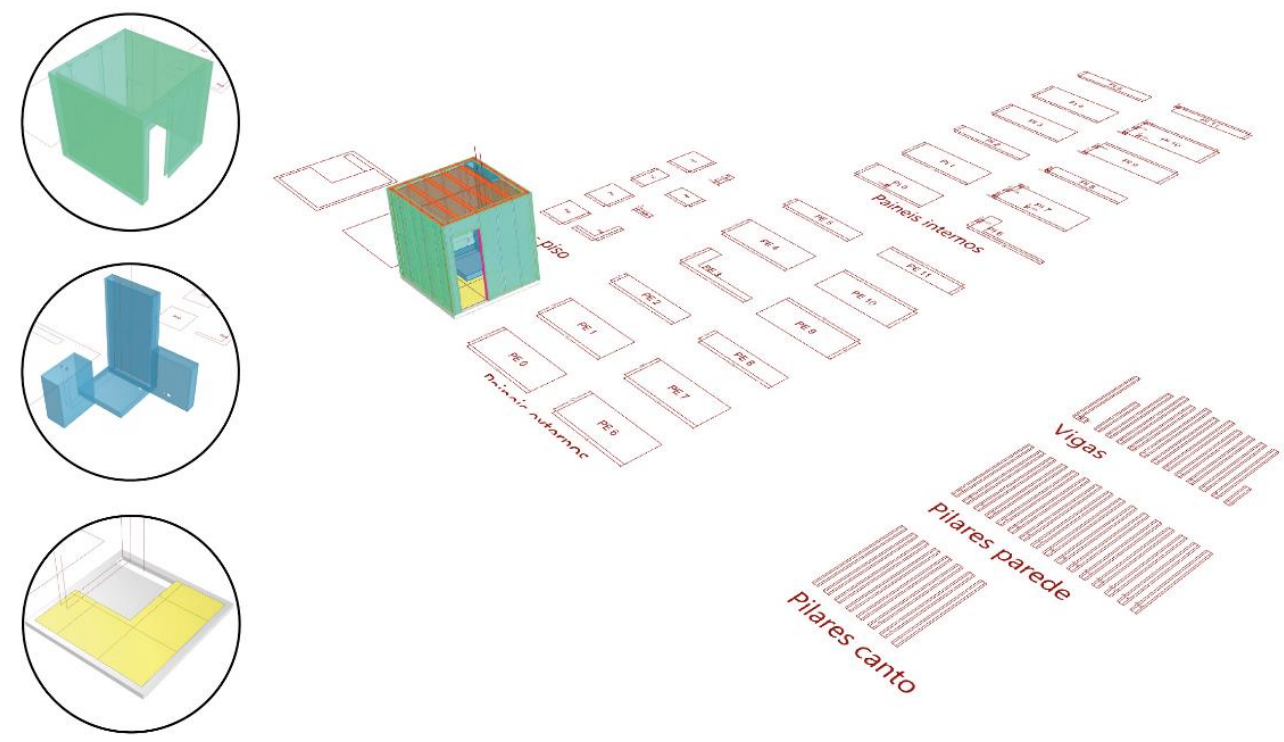

Os resultados iniciais deste trabalho foram discutidos com representantes de uma indústria brasileira de banheiros pré-fabricados. De acordo com o gerente e um arquiteto do setor, em princípio, o desenvolvimento de um sistema de automação de layout BIM permitiria a produção em massa de produtos exclusivos dentro de uma tipologia. Conforme afirmado pelos representantes desta indústria (bem como por um fabricante italiano do mesmo segmento), o custo dos documentos de construção é o principal obstáculo para permitir uma produção econômica de unidades individuais. Com o processo de geração automatizado, eles reconheceram a viabilidade da customização em massa. É importante destacar que algumas indústrias de banheiros pré-fabricados já contam com equipamentos para a fabricação digital de componentes prediais. No caso das indústrias de estrutura de aço leve, muitas empresas já estão extraindo informações do modelo BIM para serem utilizadas na fabricação com máquinas CNC. Isto é, já existe um ecossistema favorável para receber esta inteligência de projeto.

A integração completa entre arquitetura e indústria é o resultado de uma revisão metodológica do processo de projeto arquitetônico. As ferramentas atuais, como BIM, implementação de algoritmos e máquinas de controle numérico, podem facilitar a interoperabilidade dessas informações e a conexão entre o projeto e a fabricação. 0 BIM pode ser uma plataforma comum para comunicação, antecipando problemas de compatibilidade e permitindo a atualização de projetos e extração de informações para arquitetos, engenheiros e fabricantes. Algoritmos automatizam processos e diminuem significativamente retrabalho. Finalmente, as máquinas de controle numérico fecham o ciclo de automação garantindo a precisão durante a fabricação.

Este artigo aplicou esses conceitos à indústria de banheiros pré-fabricados. Embora o sistema não tenha sido implementado, os resultados indicam que a metodologia desenvolvida aumentaria a integração entre arquitetos e fabricantes bem como a capacidade de customização em massa. Este pode ser o primeiro passo para uma maior maturidade de 
utilização do BIM e maior algoritmização do processo de projeto. Processos esses que favoreceriam a consolidação da arquitetura na $4^{a}$ revolução industrial no qual existe um elevado grau de automatização. Observa-se que a mesma metodologia demonstrada aqui pode ser usada para projetos com escopos maiores e programas mais complexos.

Por se tratar de um exercício acadêmico, não tivemos a oportunidade de testar o método em toda a cadeia da construção. Porém, é possível supor, com base nas evidências da literatura, que se inserido em um projeto completo para o fluxo de trabalho da construção, o método permitiria gerar também informações para a gestão da construção, resultando em melhor resolução de conflitos, maior integração de decisões, flexibilidade do fluxo de trabalho do IFC, cronograma, orçamentação e horizontalização das decisões entre os profissionais envolvidos.

\section{Agradecimentos}

Agradecemos à Fundação de Amparo à Pesquisa do Estado de São Paulo pelo financiamento da pesquisa (processos 2017/22105-0 e 2017/09702-9); à prof. Ingrid Paoletti e ao prof. Roberto Naboni pela colaboração e às indústrias TecnoBagno, Sanika, Italcementi e Stylcomp pelas informações disponibilizadas.

\section{Referências Bibliográficas}

ABANDA, F. H.; TAH, J. H. M.; CHEUNG, F. K. T. BIM in off-site manufacturing for buildings. Journal of Building Engineering, v. 14, pp. 89-102, 2017. DOI https://doi.org/10.1016/j.jobe.2017.10.002. Disponível em: https://www.sciencedirect.com/science/article/abs/pii/S2352710217301237?via\%3Dihub. Acesso em: 03 de mar. de 2021.

ABDELMOHSEN, S. et al. A Heuristic Approach for the Automated Generation of Furniture Layout Schemes in Residential Spaces. In: Design Computing And Cognition Dcc'16, 2016, Chicago. Anais. Charlotte: Springer, 2016, pp. 483-502. Disponível em:

<https://www.researchgate.net/publication/297032365 A Heuristic Approach for the Automated Generat ion_of Furniture Layout_Schemes in Residential_Spaces. Acesso em: 08 ago. 2020.

ALPAYDIN, E. Machine Learning - The New Al. Cambridge: MIT Press, 2016. 172 p.

ANDERSON, C. et al. Augmented space planning: Using procedural generation to automate desk layouts. International Journal of Architectural Computing, v. 16, pp. 164-177, 2018. DOI

https://doi.org/10.1177/1478077118778586 Disponível em:

https://journals.sagepub.com/doi/full/10.1177/1478077118778586. Acesso em: 08 ago. 2020.

ARVIN, S. A.; HOUSE, H. Modeling architectural design objectives in physically based space planning. Automation in Construction, v. 11, n. 2, pp. 213-225, 2002. DOI https://doi.org/10.1016/S09265805(00)00099-6 Disponível em:

https://www.sciencedirect.com/science/article/abs/pii/S0926580500000996. Acesso em: 08 ago. 2020.

AS, I.; PAL, S.; BASU, P. Artificial intelligence in architecture: Generating conceptual design via deep learning. International Journal of Architectural Computing, v. 16, n. 4, pp. 306-327, 2018. Disponível em: <http://journals.sagepub.com/doi/10.1177/1478077118800982>. Acesso em: 08 ago. 2020.

BIANCONI, Fabio; FILIPPUCCI, Marco; BUFFI, Alessandro. Automated design and modeling for masscustomized housing. A web-based design space catalog for timber structures. Automation in Construction, v. 103, pp. 13-25, 2019. DOI https://doi.org/10.1177/1478077118800982. Disponível em: https://journals.sagepub.com/doi/10.1177/1478077118800982. Acesso em: 03 de mar. de 2021.

BIAGINI, C.; DONATO, V.; PELLIS, D. Preliminary Design Through Graphs: A Tool for Automatic Layout Distribution. In: ICONARP International Journal of Architecture and Planning, [S.I.], v. 2, n. 2, p. 1-13, feb. 2015. ISSN 2147-9380. Disponível em: http://iconarp.selcuk.edu.tr/iconarp/article/view/60. Acesso em: 08 ago. 2020. 
Algoritmização do projeto arquitetônico em BIM: uma aplicação na indústria de banheiros pré-fabricados

CALIXTO, V. Geração automatizada de layouts com o uso de algoritmos evolutivos: aplicações em arquitetura e urbanismo. Dissertação (Mestrado em Arquitetura e Urbanismo) - Universidade Estadual de Campinas, Campinas, 2016. Disponível em: http://repositorio.unicamp.br/jspui/handle/REPOSIP/321950. Acesso em: 03 de mar. de 2021.

CHAILLOU, S. Al + Architecture | Towards a New Approach. Dissertação (Mestrado em Arquitetura). Harvard University, 2019. Disponível em:

https://www.academia.edu/39599650/Al_Architecture_Towards_a_New_Approach. Acesso em: 13 abr. 2020.

CHANG, J. HyperCell: A Bio-inspired Design Framework for Real-time Interactive Architectures. A+BE |

Architecture and the Built Environment, [S.I.], n. 1, pp. 1-250, jan. 2018. ISSN 2214-7233. DOI:

https://doi.org/10.7480/abe.2018.1.1947. Disponível em:

https://journals.open.tudelft.nl/abe/article/view/1947. Acesso em: 08 ago. 2020.

CÔCO JÚNIOR, V. H.; CELANI, G. From the automated generation of layouts to fabrication with the use of BIM: a new agenda for Architecture in the 21st century. In: XXII CONGRESSO INTERNACIONAL DA SOCIEDADE IBEROAMERICANA DE GRÁFICA DIGITAL (SIGRADI), 7 nov. 2018, São Carlos. Anais eletrônicos. São Carlos: Blucher Design Proceedings, 7 nov. 2018. pp. 23-30. DOI: 10.5151/sigradi2018-1302. Disponível em: https://www.proceedings.blucher.com.br/article-details/-29680. Acesso em: 11 nov. 2018.

CORREIA, R.; DUARTE, J.; LEITÃO, A. GRAMATICA: A general 3D shape grammar interpreter targeting the mass customization of housing. In: 30th ECAADE CONFERENCE, 2012, Praga. Anais da 30th eCAADe Conference Volume 1 / ISBN 978-9-4912070-2-0. Praga, 2012, pp. 489-496. Disponível em:

http://papers.cumincad.org/cgi-bin/works/Show?ecaade2012 273. Acesso em: 08 ago. 2020.

DARKO et al. Artificial intelligence in the AEC industry: Scientometric analysis and visualization of research activities. Automation in Construction, v. 112, 2020. DOI: https://doi.org/10.1016/j.autcon.2020.103081. Disponível em: https://www.sciencedirect.com/science/article/abs/pii/S092658051930651X. Acesso em: 08 ago. 2020.

DAS et al. Space Plan Generator: Rapid Generation \& Evaluation of Floor Plan Design Options to Inform Decision Making. In: ACADIA // 2016: POSTHUMAN FRONTIERS: DATA, DESIGNERS, AND COGNITIVE MACHINES. Anais da 36th Annual Conference of the Association for Computer Aided Design in Architecture (ACADIA) ISBN 978-0-692-77095-5] Ann Arbor 27-29 October, 2016, pp. 106-115. [s.l.]: CUMINCAD, 2016. Disponível em: http://papers.cumincad.org/cgi-bin/works/Show?acadia16_106. Acesso em: 25 abr. 2020.

DINO, I. An evolutionary approach for 3D architectural space layout design exploration. Automation in Construction, v. 69, pp. 131-150, 2016. DOI: https://doi.org/10.1016/i.autcon.2016.05.020. Disponível em: https://www.sciencedirect.com/science/article/abs/pii/S0926580516301005. Acesso em: 08 ago. 2020.

DU, T. et al. Gaps and requirements for automatic generation of space layouts with optimised energy performance. Automation in Construction, v. 116, 2020. DOI: https://doi.org/10.1016/i.autcon.2020.103132. Disponível em: https://www.sciencedirect.com/science/article/abs/pii/S0926580519307496. Acesso em: 08 ago. 2020. DOI:

EASTMAN, Chuck. Explorations of the cognitive processes in design. Pittsburgh: Carnegie Mellon University, 1968. Disponível em:

https://www.researchgate.net/publication/235072413 EXPLORATIONS_OF_THE_COGNITIVE_PROCESSES IN DESIGN. Acesso em: 20 de ago. De 2019.

EASTMAN, C et al. Manual de BIM: um guia de modelagem da informação da construção para arquitetos, engenheiros, gerentes, construtores e incorporadores. Porto Alegre: Bookman, 2014. 481 p.

ESTRATÉGIA BIM BR. Estratégia Nacional de Disseminação do Building Information Modeling - BIM. Brasília: Mninistério da Indústria, Comércio Exterior e Serviços, [s.d.]. Disponível em:

http://www.mdic.gov.br/images/REPOSITORIO/sdci/CGMO/26-11-2018-estrategia-BIM-BR-2.pdf. Acesso em: 20 de agosto de 2019. 
FU, Q. et al. Adaptive synthesis of indoor scenes via activity-associated object relation graphs. ACM Transactions on Graphics, v. 36, n. 6, pp. 201:1-201:13, 2017. Disponível em: https://dl.acm.org/doi/10.1145/3130800.3130805. Acesso em: 08 ago. 2020.

GHAFFARIAN, M.; FALLAH, R.; JACOB, C. Organic architectural spatial design driven by agent-based crowd simulation. In: SIMAUD '18. Symposium on Simulation for Architecture and Urban Design (SIMAUD '18). Anais. Delft: Society for Computer Simulation International, 2018, pp. 1-8. Disponível em: https://dl.acm.org/doi/10.5555/3289750.3289767. Acesso em: 08 ago. 2020.

KNECHT, K; KOENIG, R. Generating floor plan layouts with k-d trees and evolucionary algorithms. In: GA2010 13TH GENERATIVE ART CONFERENCE, 2010, Milão. Anais da GA2010-13TH Generative Art Conference, 2010. Pp. 238-253. Disponível em: https://www.researchgate.net/publication/256471356_Generating_Floor_Plan_Layouts_with_Kd Trees and Evolutionary Algorithms. Acesso em: 08 ago. 2020.

KIERAN, S.; TIMBERLAKE, J. Refabricating Architecture: How Manufacturing Methodologies are Poised to Transform Building Construction. 1 edition. New York: McGraw-Hill Education, 2003.

KOENIG, R.; KNECHT, K. Comparing two evolutionary algorithm based methods for layout generation: Dense packing versus subdivision. Al EDAM, v. 28, n. 3, pp. 285-299, 2014. DOI:

https://doi.org/10.1017/S0890060414000237. Disponível em: https://www.cambridge.org/core/journals/aiedam/article/comparing-two-evolutionary-algorithm-based-methods-for-layout-generation-dense-packingversus-subdivision/CF1818B1DDA0BB4B15A72EF21F68E6AB. Acesso em: 08 ago. 2020.

LOPES et al. A constrained growth method for procedural floor plan generation. In: 11TH INTERNATIONAL CONFERENCE ON INTELLIGENT GAMES AND SIMULATION, 2010, Leicester. Anais da 11th International Conference on Intelligent Games and Simulation. Leicester, Reino Unido, 2010. Pp. 13-23. Disponível em: https://www.researchgate.net/publication/265988238 A constrained growth method for procedural floor _plan generation. Acesso em: 08 ago. 2020.

MICHALEK, J.; CHOUDHARY, R.; PAPALAMBROS, P. Architectural layout design optimization. Engineering Optimization, v. 34, n. 5, pp. 461-484, 2002. Disponível em: https://www.cmu.edu/me/ddl/publications/2002Michalek,Choudhary,Papalambros-EO-ArchLayout.pdf. Acesso em: 08 ago. 2020.

MITCHELL, W J. The Theoretical Foundation of Computer-Aided Architectural Design. Environment and Planning B: Planning and Design, v. 2, n. 2, pp. 127-150, 1975.

OESTERREICH, T.; TEUTEBERG, F. Understanding the implications of digitisation and automation in the context of Industry 4.0: A triangulation approach and elements of a research agenda for the construction industry.

Computers in Industry, v. 83, pp. 121-139, 2016. DOI: https://doi.org/10.1016/j.compind.2016.09.006. Disponível em: https://www.sciencedirect.com/science/article/abs/pii/S0166361516301944. Acesso em: 08 ago. 2020.

Oxford, Technology - Compact Oxford English Dictionary. DOI: 10.1016/j.autcon.2008.10.003. Disponível em: http://www.askoxford.com/concise oed/technology?view=uk. Acesso em 15 de Abril de 2007. Apud SUCCAR, B. Building information modelling framework: A research and delivery foundation for industry stakeholders. Automation in Construction 18, 2009. Pp. 357-375.

PREIDEL, C; BORRMANN, A. Towards code compliance checking on the basis of a visual programming language. Journal of Information Technology in Construction (ITcon), v. 21, n. 25, pp. 402-421, 2016. Disponível em: https://www.itcon.org/paper/2016/25. Acesso em: 08 ago. 2020.

RACEC, E.; BUDULAN, S.; VELLIDO, A. Computational Intelligence in architectural and interior design : a stateofthe-art and outlook on the field. Barcelona: Universitat Politècnica de Catalunya, 2016. Disponível em: https://www.cs.upc.edu/ avellido/research/RacecBudulanVellido_CCIA16.pdf. Acesso em: 08 ago. 2020.

SUCCAR, B. Building information modelling framework: A research and delivery foundation for industry stakeholders. Automation in Construction 18, 2009. Pp. 357-375. DOI: 10.1016/i.autcon.2008.10.003. Disponível em: https://www.sciencedirect.com/science/article/abs/pii/S0926580508001568. Acesso em 03 de mar. de 2021. 
VELOSO, Pedro; CELANI, Gabriela; SCHEEREN, Rodrigo. From the generation of layouts to the production of construction documents: An application in the customization of apartment plans. Automation in Construction, v. 96, pp. 224-235, 2018. DOI: https://doi.org/10.1016/j.autcon.2018.09.013. Disponível em:

https://www.sciencedirect.com/science/article/abs/pii/S0926580518304734?via\%3Dihub. Acesso em 16 de jan de 2021.

WAHBEH, Wissam. Building skins, parametric design tools and BIM platforms. In: Conference Proceedings of the 12th Conference of Advanced Building Skins, 2017, pp. 1104-1111. Disponível em:

https://www.researchgate.net/publication/320244444 Building skins parametric design tools and BIM pl atforms. Acesso em: 19 de out de 2019

WONG, S. S. Y.; CHAN, K. C. C. EvoArch: An evolutionary algorithm for architectural layout design. ComputerAided Design, v. 41, n. 9, pp. 649-667, 2009. DOI: https://doi.org/10.1016/j.cad.2009.04.005. Disponível em: https://www.sciencedirect.com/science/article/abs/pii/S0010448509001109?via\%3Dihub. Acesso em: 08 ago. 2020. 